\title{
INTERNALISASI NILAI-NILAI SPIRITUAL ISLAMI DALAM KEGIATAN PENDIDIKAN
}

\author{
*Nirwani Jumala, **Abubakar \\ *Nirwani Jumala adalah Widiyaiswara BDK Aceh dan Mahasiswa \\ Program Doktor UIN Ar-Raniry Banda Aceh \\ Email : nirwani.jumala@gmail.com \\ **Abubakar adalah Dosen L2Dikti 13 Aceh dan Mahasiswa Program \\ Doktor UIN Ar-Raniry Banda Aceh \\ Email : abubakar@serambimekkah.ac.id or abubakar_ajalil@yahoo.com
}

\begin{abstract}
Students in Islamic schools are expected to achieve the indicators of spiritual intelligence that have been predefined in the Learning Implementation Plan. However, in reality the values internalized to obtain the spiritual competence have not been able to completely change the characters of the students. This study aimed to analyze and to evaluate the achievement indicators of Islamic spiritual value competence, the methods of internalizing Islamic spiritual values, and the factors influencing the internalization of Islamic spiritual values for the students at two private Madrasah Aliyah (Islamic senior high schools), Ruhul Islam Anak Bangsa and Darul Ihsan. The study used a qualitative approach, conducted in Ruhul Islam Anak Bangsa and Darul Ihsan from April 2016 to August 2018. Data collection techniques were interview, observation, self-assessment, peer assessment, and documentation. Data analysis was done by organizing and codifying the data, enriching the theory, interpreting data, and writing the report. Findings showed that in both schools the achievement indicators of Islamic spiritual values included instilling understanding and strengthening faith ('aqidah), initiating worship routines, showing steadfast (istiqamah) and sincere (ikhla) attitudes in carrying out the practices of drawing close to Allah (taqarrub ilallāh), transforming bad behaviors into those that reflect religious values, displaying Islamic identity, and maintaining fraternity ( $u k h u w w a h)$ in everyday life. The methods of internalizing these Islamic spiritual values were carried out by lecturing and religious gathering (halaqah), discussion (jadal), storytelling ( $q i a h)$, dialogue ( $i w a r)$, conveying good messages (mau'i ah al-hasanah), self-discipline (riya $\bar{a}$ ah), role model (uswatun al-asanah), conveying excellent rewards (tabsyir), outpouring thoughts and feelings (ти $\bar{a}$ arah), encouragement and deterrence (targhib wa tarhīb), contemplation (tafakkur), pondering over (tadabbur), and concentration (tawajjuh). The success of internalizing the values was largely influenced by good relations between teachers and students, the learning methods applied, good learning environment conditions, adequate learning infrastructure and facilities, the commitment to the quality of education, and the participation of committees, founders, government, and stakeholders in the management of education. To conclude, value education should not separate spiritual and social attitudes. Social values can become spiritual when implemented under the teachings of the Qur'an and the Sunnah. The values that have been successfully internalized were those with a sense of well-being, such as the goodness rooted in a community.
\end{abstract}

\section{PENDAHULUAN}

Materi pendidikan nilai Islami memuat indikator kecerdasan spiritual, kecerdasan emosi dan kecerdasan sosial yang seimbang. Demikian juga halnya metode pendidikan nilai Islami ditentukan oleh rumusan indikator nilai itu sendiri. Esensi dasar dari pendidikan ini bermaksud menyiapkan sekelompok manusia agar menjadi penyeru terhadap kebaikan. Pendidik sebagai muslim profesional, adalah tokoh pelaku amar ma'ruf nahi mungkar dalam kegiatan pendidikan 
dan pengajaran. Semaksimal mungkin setiap pendidik harus berupaya membawa anak didik kepada hal-hal yang baik dan meninggalkan hal-hal yang tidak baik. Hendak para pendidik takut apabila meninggalkan generasi yang lemah tersebut di belakang mereka.

Lembaga pendidikan sebagai salah bengkel perbaikan karakter manusia harus mampu melakukan upaya-upaya kuratif, preventif, promotif dan rehabilitatif dalam pendidikan nilai. Mewujudkan kehadiran generasi yang baik, harus dilakukan dengan berupaya keras untuk memperbaiki dan melahirkan jiwa mereka yang baru. Jiwa yang menerima agama secara kaffah dan memiliki keyakinan transendental yang benar.

Totalitas dalam beragama seharusnya ditandai dengan adanya peningkatan kualitas keimanan. Berpegang teguh pada keyakinan dengan menjunjung tinggi ajaran syariat, adanya perbaikan akhlak menyeluruh, penguatan fisik dan penyehatan jiwa. Mengamalkan Islam secara kaffah berarti menghidupkan jiwa spiritual agar seorang muslim selamat dari alienasi pada kehidupannya. Keyakinan transendental timbul dari adanya upaya membangun spiritualisme melalui motivasi dan refreshing mental. “...spiritualitas merupakan ekspresi dari kehidupan yang sehat dan sejahtera yang dipersepsikan lebih tinggi, lebih kompleks atau lebih terintegrasi dalam pandangan hidup seseorang dan lebih daripada hal yang bersifat indrawi. Spiritual merupakan bagian esensial dari keseluruhan definisi sehat dan sejahtera bagi seorang muslim."( Hasan, 2006:287).

Pendapat di atas menjelaskan bahwa spiritual hadir dalam diri seseorang sebagai suatu kebangkitan atau pencerahan diri, dalam mencapai tujuan dan makna hidup. Proses spiritual dimulai dengan tumbuhnya kekuatan internal yang mengubah hubungan seseorang dengan Tuhan. Realitas penghambaan secara fisik akan terjadi akibat perubahan internal tersebut. Perubahan yang timbul disertai dengan meningkatnya kesadaran dan kebaikan, di mana nilainilai ke-Tuhanan termanifestasi ke luar dirinya, ketika berhubungan dengan Allah, makhlukNya dan segala yang ada di alam semesta.

Pendidikan nilai spiritual Islami mengandung materi tentang cara hidup yang sesuai dengan al-Quran dan sunnah serta memuat norma-norma dan kebudayaan. Metode dan kegiatan pendidikan nilai seharusnya difokuskan untuk tercapainya Indikator Pencapaian Kompetensi (IPK) dari materi pembelajaran.

\section{Nilai Spiritual dalam Perspektif Islam}

Nilai adalah sesuatu yang dapat dijadikan sasaran untuk mencapai tujuan yang menjadi sifat keluhuran yang terdiri dari dua atau lebih dari komponen yang satu sama lain saling mempengaruhi (Adisusilo: 2012:56). Nilai dalam Islam merupakan hasil edukasi qurani yang dikembangkan sebagai etika profetik yang digunakan sebagai suatu substansi dalam pendidikan 
Islam. Adapun konsep spiritual menurut Islam terdapat dalam surah asy-Syams: 7-10, bahwa ajaran spiritual Islami hanya dapat diperoleh melalui jalan syariah Islam yang bersumber dalam al Quran dan hadis. Allah telah memberikan potensi fasik dan takwa, manusia dapat memilihnya, apakah akan mengotori jiwanya (fasik) atau akan mensucikan jiwanya (takwa). Hal ini berarti jalan-jalan spiritual dengan mengabaikan syariah akan membuat pengikutnya jauh dari kebenaran Islam dan pelakunya tidak akan memperoleh kedamaian hakiki di dunia maupun akhirat.

Nilai spiritual Islam memiliki arah tujuan, yang secara terus menerus meningkatkan dan membimbing setiap manusia mencapai kebijaksanaan dalam menemukan hubungan yang lebih dekat dengan Allah. Spiritual dapat membantu setiap muslim menghilangkan ilusi dari gagasan salah yang berasal dari alat indra, perasaan, dan pikiran semata. Dengan kata lain spiritual Islam merupakan roh agama bagi seorang muslim, meskipun mempunyai beberapa arti, di luar dari konsep agama.

Nilai spiritual Islam adalah immateri berupa keyakinan batin, yang bersumber pada nilainilai yang terkandung dalam al-Qur'an dan as-Sunnah (Nata: 1999:80). Nilai spiritual Islam memiliki hubungan transendental intelligence, terletak dalam hati batin yang dianggap mempunyai kekuatan sakral, suci dan agung. Hati adalah hakekat spiritual batiniah, inspirasi, kreativitas dan belas kasih, yang tersembunyi di balik dunia material yang kompleks sebagai pengetahuan spiritual. Pemahaman spiritual merupakan cahaya Tuhan di dalam hati manusia yang membantu untuk melihat kebenaran. Apabila dilihat dari tinggi rendahnya nilai-nilai yang ada, nilai spiritual merupakan nilai yang tertinggi dan bersifat mutlak karena bersumber dari Allah (Frager, 2000: 70).

Aspek spiritual Islam dimulai dari proses tumbuhnya kekuatan internal yang mengubah hubungan seseorang dengan Tuhan. Akibat perubahan internal tersebut dilanjutkan dengan dengan peningkatan realitas fisik. Konotasi lain perubahan akan timbul pada diri seseorang dengan meningkatnya kesadaran diri, di mana nilai-nilai ke-Tuhanan di dalam akan termanifestasi keluar melalui pengalaman dan kemajuan diri. Hal ini tidak terlepas dari upaya yang gigih untuk berpegang teguh pada ajaran dalam kitab suci (al-Qur'an).

\section{Pendidikan Nilai Spiritual dalam Islam}

Setiap orang adalah makhluk yang sadar akan dirinya sendiri, yang memiliki kedudukan sebagai satu-satunya makhluk hidup yang memiliki pengetahuan, budaya dan kemampuan membangun peradaban. Oleh karena itu setiap orang mempunyai cita-cita dan merindukan sesuatu yang ideal. Dengan kata lain orang yang mempunyai cita-cita, selalu berusaha mengubahnya menjadi sesuatu yang apa adanya menjadi sesuatu yang semestinya. 
Kelangsungan hidup setiap orang selalu berkaitan dengan masalah nilai (value). Maka dalam kegiatan pembelajaran dan internalisasi nilai menurut pendidikan Islam, ada lima hal mendasar yang harus diperhatikan (Ali dan Luluk, 2007: 267), yaitu: 1. Proses transformasi dan internalisasi dalam pelaksanaan pendidikan Islam harus dilakukan secara bertahap, berjenjang dan terus menerus. Upaya pemindahan, penanaman, pengarahan, pengajaran, dan pembimbingan yang dilakukan secara terencana, sistematis, dan terstruktur dengan menggunakan pola dan sistem tertentu. 2. Ilmu pengetahuan dan nilai-nilai berupa upaya yang diarahkan kepada pemberian dan penghayatan serta pengalaman ilmu pengetahuan dan nilainilai. 3. Anak didik diberikan pendidikan yang memperkuat potensi kebaikan ruhani. 4. Tugas pendidikan Islam menumbuhkan, mengembangkan, memelihara dan menjaga potensi fi rah manusia, agar tumbuh dan berkembang sesuai dengan tingkat kemampuan, minat, dan bakatnya. 5. Tujuan akhir pendidikan Islam adalah untuk mencapai keselarasan dan kesempurnaan dalam segala aspek hidup yaitu terbentuknya insōn kamīl.

Hal ini berarti pendidikan mencakup segala hal yang berhubungan dengan kehidupan manusia. Pendidikan dilaksanakan secara praktis dalam kegiatan pembelajaran dan internalisasi nilai. Peningkatan kemampuan intelektual yang sempurna harus diringi dengan upaya menumbuhkan, mengembangkan, menjaga potensi kebaikan peserta didik.

Pendidikan nilai yang dilakukan dalam bentuk kegiatan pembelajaran mengandung seperangkat tujuan, materi dan metode yang mengarahkan peserta didik menjadi hamba Allah yang kaffah dalam mengamalkan nilai-nilai Islam. Dalam surah al-Baqarah: 207, disebutkan bahwa pengamalan Islam yang kaffah ditandai dengan peningkatan kualitas keimanan yang menjunjung tinggi ajaran syariat, adanya perbaikan akhlak yang menyeluruh, penguatan fisik dan penyehatan jiwa. Upaya transendental ini mengandung nilai-nilai spiritual untuk membentengi anak didik dari berbagai jalan kemaksiatan dan kesesatan.

Pendidikan dan pembelajaran harus dihubungkan dengan upaya perubahan untuk menghadirnya pribadi yang senantiasa konsisten dalam berbuat baik dan saling memperbaiki. Hasil yang diharapkan dari pendidikan nilai adalah peserta didikmenghayati makna nilai tersebut, sehingga mereka senantiasa menabur benih-benih kebaikan dalam segala aktivitas hidupnya. Selanjutnya dengan nilai kebaikan tersebut akan tumbuh dan menyebar dalam komunitas yang lebih besar.

\section{Arah dan Tujuan Pendidikan Nilai Spiritual Islam}

Pendidikan nilai spiritual Islam yang dilaksanakan oleh lembaga pendidikan memiliki arah dan tujuan yang sesuai dengan tujuan pendidikan nasional. Pendidikan nilai spiritual Islam juga harus tepat sesuai dengan hasil analisis kondisi yang lalu, kondisi sekarang dan prognosa 
kondisi di masa yang akan datang. Dengan kata lain kondisi dan kebutuhan masyarakat terhadap nilai tersebut harus dipilih berdasarkan prioritas nilai yang harus diinternalisasikan.

Pendidikan nilai spiritual Islami berfungsi sebagai penuntun bagi seseorang dalam menerapkan perilaku-perilaku baik yang sesuai dengan tuntunan syariat, dalam kehidupan pribadi kehidupan, bermasyarakat, berbangsa dan bernegara. Dalam jangka pendek pendidikan nilai spiritual Islam hendak mewujudkan output yang beriman, bertakwa dan berakhlak mulia. Dalam sasaran jangka panjang, pendidikan nilai spiritual Islami akan melahirkan outcame yang beradab. Nilai-nilai spiritual Islami yang berisi seluruh nilai-nilai kebaikan menghiasi perilaku hidup. Mereka ibarat sumbu pemantik percikan peradaban yang mengulang sejarah Islam periode "the golden age".

Terdapat dua hal pokok yang harus diperhatikan agar arah dan tujuan tersebut dapat dicapai, yaitu: 1. Kesesuaian antara visi-misi, orientasi, tujuan, dengan kecerdasan komplit yang ingin dikembangkan. Struktur, komposisi, jenis, jenjang, dan jumlah mata pelajaran lengkap dengan bobot isi dan waktu pelajaran merupakan penjabaran lebih lanjut dari visi, misi, orientasi dan tujuan yang ingin dicapai menurut level atau tingkat-tingkat kelas. 2. Seiring prinsip otonomi dalam menyelenggarakan pendidikan bermutu, maka sebaiknya lembaga pendidikan sebaiknya merencanakan kurikulumnya sendiri sesuai dengan pandangannya, namun harus tetap dalam rambu-rambu kebangsaan, kenegaraan dan matched dengan tantangan lokal dan global (mastuhu, 2009: 101).

Kecerdasan komplit dapat dipahami sebagai potensi kecerdasan yang dimiliki manusia seperti kecerdasan intelektual, kecerdasan emosional, kecerdasan spiritual. Berorientasi pada kecerdasan religi, keseluruhan kecerdasan ini, hanya dapat dicapai melalui sekolah kehidupan. Nilai-nilai nyata dari kehidupan manusia dapat dipelajari secara utuh sehingga membentuk karakter yang mampu memahami dan menerima dengan arif segala sunnatullah di alam semesta.

Pendidikan dan pembelajaran seharusnya bukan hanya berorientasi pada proses transfer pengetahuan-agama, akan tetapi harus sampai pada pembinaan komitmen dan internalisasi nilai. Pengetahuan yang tidak seimbang dengan pemahaman dan pengamalan agama artinya pudar atau hilangnya unsur spiritual dalam kehidupan.

\section{Potensi dan Indikator Kecerdasan Spiritual Islam Bagi Anak didik}

Potensi spiritual adalah fi rah bagi manusia, artinya potensi spiritual adalah sesuatu yang dibawa lahir. Dinyatakan dalam surah ar-Rūm: 30, bahwa fi rah merupakan jiwa kemanusiaan yang perlu dilengkapi dengan tabiat beragama. Dalam hal ini, Sayyid Qutub berpendapat bahwa fi rah kemanusiaan dan tabiat beragama merupakan relasi yang utuh karena keduanya merupakan ciptaan Allah pada diri manusia sebagai potensi dasar yang memberikan hikmah, 
mengubah diri ke arah yang lebih baik, mengobati jiwa yang sakit dan meluruskan diri dari berpaling (Qutb, tt: 453).

Fi rah merupakan asal kejadian atau bawaan lahir seorang manusia. Hal ini berarti bahwa setiap individu memiliki potensi watak yang berbeda. Menurut al-Ghazali, watak manusia terbagi kepada empat macam yaitu: 1 . Manusia bodoh yang tidak dapat membedakan yang benar dan yang salah, antara yang indah dengan yang buruk. Manusia model ini udah sekali dirubah watak dan tabiatnya. 2. Manusia yang mengetahui akan sesuatu keburukan yang buruk, tetapi tidak mau melaksanakan suatu kebaikan bahkan kadangkala melakukan keburukan dengan dorongan nafsunya. Watak manusia model ini dapat dirubah dengan melatih diri untuk menghindarkan perbuatan yang buruk dan membiasakan diri untuk berbuat suatu kebaikan. 3 . Manusia yang telah mempuyai keyakinan bahwa buruk itu baik dan indah baginya manusia model ini sulit diperbaiki, kalaupun dapat hanya sebagian kecil saja. 4. Manusia yang berkeyakinan bahwa mengerjakan sesuatu kejahatan merupakan suatu kebanggaan tersendiri. Manusia model ini hampir tidak dapat didik dan diperbaiki wataknya (Shihab, 2006: 52).

Berdasarkan kondisi watak manusia tersebut, potensi spiritual yang ada dalam setiap diri seseorang, akan membimbingnya untuk menerima nilai-nilai kebaikan yang ditanamkan. Setiap orang yang berada di bawah naungan transendental mampu beradaptasi, berinteraksi dan bersosialisasi dengan lingkungan rohaninya yang bersifat ghaib. Kondisi watak yang dilindungi kekuatan spiritual inilah, yang menyebabkan seseorang mampu mengenal Tuhannya. Sesorang dapat merasakan hikmah dan nikmat dari ibadah-ibadahnya dan segala kebaikan yang dilakukannya berdasarkan panduan syariat.

Dalam konsep Islam ada beberapa indikator yang menunjukkan bahwa seseorang telah memperoleh kecerdasan spiritual, antara lain; dekat, mengenal, cinta berjumpa Tuhannya, selalu merasakan kehadiran dan pengawasan Tuhannya dimanapun dan kapanpun, tersingkapnya alam ghaib (ilmu mukōsyafah), memiliki sifat iddiq, memiliki sifat iddiq, memiliki sifat amōnah, memiliki sifat tabligh, memiliki sifat fa anah, memiliki sifat istiq $\bar{\alpha} m a h$, memiliki sifat tulus ikhlas, memiliki sifat bersyukur, malu berbuat dosa." (Adz Dzakiey, 206: 287-296).

Berdasarkan kutipan di atas, dapat dijelaskan bahwa rasa dekat, mengenal, cinta berjumpa Tuhannya adalah indikator utama pendidikan nilai spiritual Islam. Kecintaan seorang hamba kepada Allah, tidaklah dapat diserupakan dengan kecintaan, kedekatannya kepada sesama makhluk. Hal ini sebagaimana tercantum dalam surah al-Baqarah: 186, bahwa Allah berada sangat dekat dengan hamba-hamba-Nya yang beriman dan berada dijalan spiritual (jalan kebenaran). Sebagai buktinya, orang-orang spiritual menyandarkan harapannya kepada Allah, sehingga mereka selalu berdoa dan meminta sebagai bukti mereka dekat dengan Allah. 


\section{Metode Internalisasi Nilai Spiritual Islami}

Nabi Muhammad Saw telah berhasil menjalankan misinya dalam menyempurnakan akhlak manusia hanya dalam waktu kurang dari 23 tahun, sehingga masyarakat jahiliyah berganti menjadi masyarakat madani. Pada masa awal perkembangan sejarah Islam, kunci utama keberhasilan dakwah Rasulullah adalah keagungan akhlak, sebagaimana disebutkan dalam surah al-Qalam: 4, bahwa Nabi Muhammad Saw adalah figur teladan yang memenuhi kriteria sempurna dalam mendidik manusia.

Nabi Muhammad mendidik para sahabat dengan al-Qur'an, sehingga memiliki karakter sebagai pengikut terbaik. Adab dan karakter mulia Rasulullah Saw disertai dengan sikap rendah hati yang luar biasa, meskipun status dan kedudukan Beliau sangat tinggi. Rasululah Saw bahkan mengucapkan salam kepada anak-anak dan bermain dengan mereka dijalan Munajid, 2018: 565).

Rasulullah Saw dengan kepribadiannya yang mulia berhasil mendidik para sahabat menjadi pembuka pintu gerbang dalam membangun masyarakat berperadaban tinggi. Sejarah Islam mencatat keberhasilan Rasulullah Saw ini dalam tinta emas tamaddun. Belajar dari keberhasilan Rasulullah Saw tersebut dapat disimpulkan bahwa metode pendidikan Nabi sangat berpengaruh untuk keberhasilan internalisasi nilai dan pembentukan karakter manusia.

Upaya internalisasi nilai spiritual Islami yang sesuai dengan metode pendidikan Nabi diberikan sesuai dengan jenjang pendidikan yang sedang ditempuh peserta didik, karena pada setiap jenjang pendidikan tersebut, peserta didik mengalami tahapan psikologi perkembangan yang spesifik. Metode-metode tersebut seharusnya dikembangkan lebih lanjut dengan merujuk pada ayat-ayat al-Qur'an yang sesuai dengan substansi ilmu yang dipelajari, sehingga peserta didik tidak saja memperoleh pengetahuan, tetapi diharapkan memperoleh keberkahan dari ilmu itu sendiri.

Menurut konsep pendidikan Islam, buah dari ilmu adalah terbentuknya sikap mulia, yang membedakan antara orang terdidik dengan orang bodoh. Pendidikan Islam meramu ilmu, iman dan amal saleh menjadi sebuah paket yang sempurna. Hal ini tentu berbeda dengan konsep yang menganggap seseorang terdidik cukup diukur dengan kualitas kognitifnya saja. Diantara metode pendidikan nilai spiritual Islam adalah metode uswatun Hasanah, metode Hiwar, Metode Riyadhah, Metode Qissah, metode targhib wa tarhib.

\section{Keberhasilan Internalisasi Nilai Spiritual Islam}

Menurut pendidikan Islam hubungan dalam pembelajaran dibangun atas dasar $t a^{\prime}$ 'im dari peserta didik dan kasih sayang yang tulus dari pendidik. Proses internalisasi nilai dimulai 
dengan pengenalan dan renungan nilai, pengkajian nilai, sehingga pada gilirannya menampakkan diri dalam pengungkapan dan penghayatan nilai.

Upaya untuk mengajarkan nilai-nilai spiritual Islam, dapat dikatakan berhasil, jika nilainilai tersebut mampu menjadi sikap hidup seseorang. Seluruh kegiatan yang dilakukan pendidik dalam menanamkan dan menumbuhkembangkan nilai harus memberikan dampak peningkatan kualitas spiritual pada keduanya (pendidik dan peserta didik) (Muhaimin, 2004: 41).

Manusia dikaruniai religious instinct, sehingga dapat dikenal sebagai godly and religious beings \{Ramayulis, 2006:46). Fi rah beragama ini merupakan disposisi (kemampuan dasar) yang mengandung kemungkinan atau peluang untuk berkembang, namun demikian, mengenai arah kualitas perkembangan agama pada anak didik sangat bergantung kepada proses pendidikan yang diterimanya.

Keberhasilan internalisasi nilai-nilai spiritual Islam dipengaruhi oleh dua faktor yang mempengaruhi individu yaitu faktor internal ( $f$ rah) dan faktor ekternal (lingkungan keluarga, lingkungan sekolah dan lingkungan masyarakat). Setiap manusia yang lahir ke dunia, baik yang masih primitif, bersahaja, maupun kapitalis, baik yang lahir dari orangtua yang saleh maupun jahat, mereka pasti memiliki naluri beragama.

\section{METODE PENELITIAN}

\section{Lokasi dan Pendekatan Penelitian}

Penelitian ini telah dilakukan pada MAS Ruhul Islam Anak Bangsa dan Madrasah Aliyah Darul Ihsan telah dilaksanakan mulai bulan April 2016 s/d Agustus 2018. Penelitian ini menggunakan pendekatan kualitatif, di mana temuan-temuan penelitian tidak diperoleh melalui prosedur statistik, sehingga tidak dirancang secara baku (Lexy J. Moleong 2007 : 3). Penelitian kualitatif mengembangkan pengertian, konsep-konsep, yang pada akhirnya menjadi teori (grounded theory research). Penelitian dilakukan pada obyek yang berkembang apa adanya, tidak dimanipulasi oleh peneliti dan kehadiran peneliti tidak begitu mempengaruhi dinamika pada obyek tersebut.

\section{Sumber Data Penelitian}

Sumber data penelitian atau responden dalam penelitian ini adalah orang-orang yang terlibat langsung, yang dapat memberi data serta informasi sesuai dengan fokus dan tujuan penelitian. Informan dalam penelitian ini terdiri dari: a. Informan kunci yaitu mereka yang memiliki berbagai informasi pokok yang diperlukan dalam penelitian yaitu Kepala Madrasah atau Wakil Kepala Madrasah Bidang Pengajaran/Pengasuhan. B. 
Informan utama yaitu mereka yang terlibat langsung dalam interaksi memberikan informasi yaitu guru dan anak didik. c. Informan tambahan yaitu mereka yang dapat memberikan informasi walaupun tidak terlibat langsung dalam fokus penelitian seperti komite (orangtua/ masyarakat/alumni).

\section{Teknik Pengumpulan Data}

Pengumpulan data merupakan kegiatan inti dari sebuah penelitian, karena penulisan laporan penelitian hendaknya bersandar pada data dan fakta yang akurat. Teknik pengumpulan data yang digunakan dalam penelitian ini dapat diuraikan sebagai berikut:

a. Wawancara (interview), Dalam penelitian ini peneliti melakukan wawancara dengan Kepala Madrasah, wakil kepala Madrasah Bidang kurikulum/pengajaran, guru dan anak didik. Adapun instrumen pengumpulan data yang digunakan adalah pedoman wawancara dan media recorder.

b. Observasi, Observasi atau pengamatan merupakan suatu teknik atau cara mengumpulkan data dengan jalan mengadakan pengamatan terhadap kegiatan yang sedang berlangsung. Kegiatan tersebut bisa berkenaan dengan kondisi umum lokasi penelitian, kegiatan pembelajaran kurikuler dan ekstrakurikuler yang berhubungan dengan internalisasi nilai spiritual dalam pembelajaran pada MAS RIAB dan MAS Darul Ihsan Kabupaten Aceh Besar.

c. Penilaian diri dan penilaian antar teman, Hasil penilaian diri dan penilaian antar teman digunakan sebagai data konfirmasi. Instrumen yang digunakan sesuai dengan lampiran pada RPP guru.

d. Analisis Dokumen. Analisis dokumen merupakan proses pengambilan data yang sudah tersedia sebelumnya. Sejumlah utama yang dianalisis seperti catatan perilaku siswa/ buku kasus, data pemanggilan orang tua, buku kronologi (Bimbingan Konseling), jurnal pembelajaran, deskripsi nilai spiritual. Disamping itu peneliti juga melakukan analisis dokumen untuk mendapatkan data tambahan seperti profil madrasah, laporan Badan Penelitian dan Pengembangan Madrasah Kementerian Agama. 


\section{Teknik Analisa Data dan Uji Kredibilitas Data}

Analisis data dilakukan dengan teknik analisis tematik, yaitu metode untuk mengidentifikasi, menganalisis, dan melaporkan pola-pola atau tema dalam suatu data untuk menafsirkan berbagai aspek tentang topik penelitian.

Analisis data meliputi kegiatan mengerjakan data, menata, membaginya menjadi satuan-satuan yang dapat dikelola, kemudian mencari pola sehingga dapat ditemukan hal yang paling penting terutama dalam mengorganisasikan data sehingga dapat tersusun dengan baik dan penelitian dapat membuahkan hasil yang baik. Tahap analisis data sebagai berikut: a. Menyiapkan data yang akan dianalisis dengan cara dikelompokkan, b. Mengidentifikasi item-item tertentu yang relevan dengan topik studi, c. Mengurutkan data berdasarkan kesamaan tema, d. Menguji kesamaan tema dan memformulasikan dalam suatu kategori tertentu, e. Memperhatikan masing-masing tema secara terpisah dan hati-hati untuk menguji kembali masing-masing transkrip jawaban yang memiliki tema yang sama, e. Menggunakan semua material yang berhubungan dengan masingmasing tema untuk membuat tema akhir yang berisi sebuah nama kategori dan pengertiannya bersama dengan data pendukung dan menyeleksi data yang relevanuntuk dibuat menjadi illustrasi dan melaporkan masing-masing tema.

Namun demikian sebelum sampai ke tahap akhir yaitu penulisan hasil penelitian, temuan dalam penelitian belum mampu memberikan gambaran yang representatif tentang metode internalisasi nilai spiritual dalam pembelajaran. Oleh karena itu peneliti merasa perlu melakukan triangulasi.

Triangulasi sebagai pendekatan multimetode, dilakukan pada saat mengumpulkan dan menganalisis data. Secara teori triangulasi meliputi empat hal, yaitu; (1) triangulasi metode, (2) triangulasi antar-peneliti (jika penelitian dilakukan dengan kelompok), (3) triangulasi sumber data, dan (4) triangulasi teori (Bungin M. Burhan 2009).

Peneliti melakukan triangulasi teori yaitu peneliti melakukan kajian secara lebih mendalam pemikiran-pemikiran para ahli yang berhubungan dengan temuan. Peneliti juga melakukan triangulasi sumber pada Madrasah Aliyah Ruhul Islam Anak Bangsa. Kegiatan ini dilaksanakan pada saat kegiatan haflah takhrij ke XVIII tanggal 15 April 2016, sumber data yang diwawancarai adalah ketua yayasan Ruhul Islam Anak 
Bangsa (Prof. Dr. Syamsuddin Mahmud). Data juga diambil dari kata-kata sambutan Ketua Komite pendidikan Madrasah Aliyah Ruhul Islam Anak Bangsa, Kepala Kantor Wilayah Kementerian Agama Propinsi Aceh dan orang tua peserta didik.

Triangulasi sumber juga dilakukan pada beberapa orang alumni MAS Darul Ihsan. Kegiatan triangulasi sumber ini peneliti lakukan untuk memperkuat temuan atau hasil penelitian. Sebelum diajukan untuk seminar hasil penelitan, peneliti melakukan klarifikasi kembali terhadap data yang telah dituliskan dalam laporan penelitian kepada sumber data utama di MAS RIAB dan MAS Darul Ihsan.

\section{PEMBAHASAN}

Hasil internalisasi nilai spiritual Islami yang diharapkan dari sebuah lembaga pendidikan bukanlah dalam rentang proses atau output, melainkan sebagai outcame. Pembelajaran nilai pada hakikatnya tidak boleh memisahkan antara sikap spiritual dan sosial. Nilai sosial tetap bernilai spiritual manakala dilakukan karena patuh pada ajaran yang terkandung dalam alQur'an dan sunnah. Kegiatan pembelajaran nilai spiritual Islami, diharapkan mampu membentuk kepribadian dan menjadi qudwah bagi ummat, dengan jiwa transendental yang telah tertanam.

Dimensi transendental dalam pendidikan adalah bagian dari fi rah kemanusiaan sebagai bentuk persentuhan dengan kebesaran Tuhan. Dalam perkembangan saat ini, dimana sebagian orang berpendapat sebagai zaman peradaban postmodernism, muncul satu ciri khas yaitu semakin menguatnya spiritualisme. Kondisi yang muncul adalah agama menyatu kembali dengan dunia, sehingga orang-orang tertarik untuk mencari dan menemukan Tuhan. Adapun bagi umat Islam, hal ini bukanlah sesuatu yang baru, Islam mengajarkan bahwa urusan akhirat dan dunia bukan dua hal yang terpisah.

Pendidikan yang dilandasi nilai-nilai spiritual Islami, merupakan upaya membuka lahan amal bagi masa depan yang panjang di akhirat kelak. Setiap lembaga pendidikan terutama yang berbasis pendidikan agama Islam, memiliki indikator dan metode untuk mewujudkan hadirnya dimensi transendental ini dalam pendidikan. Nilai-nilai yang diaplikasikan adalah bagian dari kompetensi sikap yang diharapkan oleh pendidikan nasional bagi penguatan karakter bangsa.

Pendidikan nilai spiritual Islami adalah upaya pembinaan watak peserta didik baik secara disengaja maupun tidak disengaja yang disertai dengan penanaman nilai dari ajaran agama Islam. Internalisasi nilai-nilai spiritual Islami dalam kegiatan pendidikan dan pembelajaran merupakan upaya yang dilakukan oleh pendidik dalam upaya menghasilkan peserta didik dengan menjadi karakter (characterization) manusia beriman dan bertakwa. 


\section{KESIMPULAN}

Pendidik sangat bertanggungjawab dalam keberhasilan internalisasi nilai di lembaga pendidikan, sebagaimana besarnya tanggungjawab keluarga dalam lembaga in-formal dan masyarakat di lembaga non-formal. Berbeda halnya dengan lembaga pendidikan in-formal dan non-formal, dalam lembaga pendidikan formal pendidik memiliki panduan standar dalam penerapan kurikulum yang telah ditetapkan. Panduan standar ini bukanlah sesuatu yang baku. Setiap lembaga pendidikan dan pendidik dituntut mampu mengembangkan kurikulum tersebut sesuai dengan kondisi dan kebutuhan peserta didik. Pengembangan kurikulum bukan hanya difokuskan pada aspek pengetahuan, akan tetapi aspek sikap. Bahkan dalam aspek sikap ini, lembaga pendidikan seharusnya memiliki fokus pengembangan dan perhatian khusus terhadap penguatan karakter peserta didik pada aspek tertentu.

Pengembangan karakter peserta didik, tidak akan pernah berhasil jika pendidik sendiri tidak berkarakter. Hal inilah yang sangat ironis dalam dunia pendidikan formal hari ini. Pendidik menuntut tertanamnya nilai kebaikan dari peserta didik, sementara mereka sendiri mengabaikan nilai tersebut dalam karakter dirinya. Pada saat bertugas di suatu lembaga pendidikan, seharusnya pendidik tidak hanya dituntut mahir dalam kompetensi profesional, tetapi juga mantap dalam kompetensi kepribadian, sosial dan pedagogik.

Nilai-nilai yang berhasil ditanamkan pada dasarnya adalah nilai karakter yang memiliki nasab. Dengan kata lain kebaikan yang berakar dalam suatu komunitas baik di lingkungan keluarga, sekolah dan masyarakat akan mudah ditanamkan secara turun temurun, apabila nilai tersebut sudah diadopsi, untuk dijadikan pegangan dan tuntutan.

Berbeda halnya dengan pendidikan aspek pengetahuan dan ketrampilan yang membutuhkan beragam alat, media, sarana pendukung, dalam pembelajaran dan internalisasi nilai pada dasarnya tidak membutuhkan terlalu banyak alat dan media. Alat dan media internalisasi nilai yang terbaik adalah kepribadian pendidiknya.

\section{DAFTAR PUSTAKA}

- Abdullah Nashih Ulwan, Pendidikan Anak Dalam Islam, terjemahan Jamaluddin Miri, Jakarta: Pustaka Amani, 2003.

- Abuddin Nata, Metodologi Studi Islam, (Jakarta: Grafindo Persada, 1999.

- Ali M. dan Luluk Y. R., Paradigma Pendidikan Universal di Era Modern dan Post-Modern; Mencari Visi Baru atas Realitas Baru Pendidikan Kita), (Jakarta: Pustaka Setia, 2004), hlm.267. 
- Aliah B. Purwakania Hasan, Psikologi Perkembangan Islami, Menyingkap Rentang Kehidupan Manusia dari Prakelahiran Hingga Prakematian, (Jakarta: Raja Grafindo Persada, 2006), hlm.287.

- Hamdani Bakran Adz Dzakiey, Prophetic Intelligence: Kecerdasan Kenabian, Mengembangkan Potensi Robbani Melalui Peningkatan Kesehatan Ruhani, cet.2, (Yogyakarta: Pustaka al-Furqan, 2006).

- M. Quraisy Shihab, Tafsir Al Misbah, cet.XII, (Jakarta: Lentera, 2006), hlm.52

- Mas Udik Abdullah, Meledakkan IESQ dengan Langkah Takwa dan Tawakkal, cet. I, (Jakarta: Zikra, 2005).

- Mastuhu, Menata Ulang Pemikiran Sistem Pendidikan Nasional dalam Abad 21, (Jakarta: Pustaka Setia, 2009), hlm.101.

- Muhamimin, Wacana Pengembangan Pendidikan Islam, (Yogyakarta: Pustaka Pelajar, 2004), hlm. 41.

- Muhammad Shalih al-Munajjid, Kaifa 'amalahum, Seni Berinteraksi Rasulullah terjemahan Noor Cholis dan Putri Aria Miranda, (Solo, Aqwam Media, 2018), hlm.565.

- Muhmidayeli, Filsafat Pendidikan Islam, Cet.I, (Yogyakarta: Aditya Media, 2005), hlm.115.

- Ramayulis, Psikologi Agama, (Jakarta: Radar Jaya, 2006), hlm.46

- Richard A. Bowell, The 7 Steps of Spiritual Intelligence: The Practical Pursuit of Purpose, Success and Happiness, (Nicholas Brealey Publishing, 2004).

- Robert Frager, Nafs in Sufism Psychology, terjemahan Hasmiyah Rauf, (Jakarta: Serambi Ilmu, 200), hlm.7

- Sayyid Qutub, Tafsir Fi Zilal Al Quran, Juz VI, (Libanon, Darul A ya, t.t), hlm.453.

- Sutarjo Adisusilo, Pembelajaran Nilai-nilai Karakter Konstruktivisme sebagai Inovasi Pendekatan Pembelajaran Afektif,, (Jakarta: Rajawali Persada, 2012), hlm.56.

- Syaikh Abdushomad al-Palembani, Hidayatus Shalikin Mengarungi Samudera Ma'rifat, (Surabaya: Pustaka Hikmah Perdana, 2013

- Taufik Pasiak, Revolusi IQ/EQ/SQ, Menyingkap Rahasia Kecerdasan Berdasarkan al-Quran dan Neurosains Mutakhir, cet.I (Bandung: Mizan, 2002). 